\title{
Using applications programs in a university to build human capacity for Information Technology
}

\author{
D. Arganbright \\ Professor and Head Department of Mathematics \\ University of Papua New Guinea \\ PO Box 320, University PO, NCD 134, Papua New Guinea \\ Tele + 675 3267414; Fax + 6753267187 \\ E-mail:100353.163@Compuserve.com
}

\begin{abstract}
To equip students and staff of the University of Papua New Guinea (UPNG) with technology skills needed in the workplace, and in school and university settings, UPNG's Mathematics Department is modernizing its curriculum to incorporate technology. The major vehicle for change is the creative use of Microsoft Office, and courses were developed not only to provide job skills but also to emphasize problem solving and critical thinking, mathematical applications and communication skills. Four components - computer literacy for students, spreadsheets for mathematics and statistics, community outreach, and staff development with word processing, spreadsheets, and databases - are important elements of the university's curriculum.
\end{abstract}

\section{Keywords}

Capacity building, developing countries, higher education, software, spreadsheets

\section{INTRODUCTION}

Papua New Guinea is a rapidly developing nation in the South Pacific. Like many other developing countries, it is grappling with the need to find ways to effectively expand its Information Technology (IT) capabilities in spite of 
A primary goal of the Mathematics Department is to provide all university students with a good foundation in IT skills early in their university careers through the Introduction to Computing course. For several years the course emphasized programming but has gradually shifted to the use of application programs. Students now learn how to use Windows 95, Word, Excel, and Access.

Many students touch a computer for the first time in the course and so initial sessions concentrate on the techniques of using a computer, mouse and keyboard. Beginning sessions also stress the need for students to plan what they will be doing in a laboratory session before they sit down at a computer. Subsequent weeks are spent developing skills in the use of the application programs but the course has other educational purposes. For example, while learning to use Word students learn how to create documents that include graphics, equations and other significant features. Similarly, Excel is used to teach problem solving and analysis - skills that are often lacking in students' previous educational experiences. Spreadsheet examples are drawn from finance, population growth, epidemics, heat flow, mathematics and statistics, giving students insights into many different disciplines (Cartwright, 1993). Students generally find the course to be both interesting and useful, and become aware that they are acquiring skills that they can apply to their academic studies and to tasks they will encounter in the workplace.

Introduction to Computers is taught in two large 2-hour lectures and one 2hour tutorial per week. Students are allocated at least five hours a week to work on computers in the laboratories. In 1997 improved staffing levels and the opening of a new central laboratory have enabled the department to use tutors to conduct small weekly hands-on laboratory tutorial sessions. The course is offered each semester to about 100 external students as well as 200 second and third year full-time students on the main campus. Forty second and third year Health Science students take a similar course. Future enrollments undoubtedly will increase since the university plans to make a similar course a requirement for all first year students .

\section{INCREASING STAFF COMPUTING CAPABILITIES}

The Mathematics Department has also provided instruction to the university's staff to assist them in increasing their computing capabilities through an introductory 6-session short course. Taught in the senior lab and meeting one hour a week, the class consists of one session on Windows 95, two sessions on word processing using Word, two sessions on spreadsheets using Excel and a concluding session where students learn to integrate the two programs. During the last two years the class has been offered frequently and over 200 staff members have attended. Both the lecturers and attendees participate on a voluntary basis.

The course provides staff with hands-on experience. Technology novices gain familiarity with computers and experienced computer users upgrade their skills by working in a Windows environment. Initially the sessions were 
conducted with two participants sharing a computer but that arrangement detracted from the goal of providing staff with intensive hands on experience. Now additional computers are placed temporarily in the lab so that each participant has his/her own computer. If the classes are to be successful staff must have adequate time to practice their new skills, so the department's senior lab is made available for staff at designated times.

Some classes are held after work hours, others at noon and others during work hours. Attendees include random cross sections of university personnel, with support, administrative and academic staff comprising each class. Although a heterogeneous composition of the classes has worked well, a few attendees say that it would be better to form homogeneous groups with participants having similar job functions and skill levels.

Staff members have requested additional courses and the department has been able to accommodate many requests. Two courses for advanced instruction in Word and Excel have been offered as well as an elementary five session course in Access teaching an introduction to database concepts. A two-session overview of PowerPoint is also a popular course.

The Mathematics Department also presents special short courses designed specifically for academic purposes. One course teaches the use of equations and graphics features in Word and Excel for the preparation of professional papers and classroom notes as well as the use of PowerPoint for classroom lectures and professional presentations. Other classes illustrate the use of Excel as an academic tool for mathematical modeling, research, classroom teaching and professional publications. Applications for a wide range of disciplines physics, population studies, genetics, economics, epidemics, numerical methods, and operations research and computer visualization - are presented in the courses.

Microsoft Office provides the computing tools that support, administrative and academic staff require to perform their jobs, and the attendees appreciate the fact that the courses are offered on a voluntary basis. The extensive notes provided are well received by the university community and the Mathematics Department's efforts to present the short courses have been well received.

\section{PROVIDING TECHNOLOGY RESOURCES TO THE PUBLIC}

For many years the Mathematics Department advertised the Introduction to Computing and other computer science courses to members of the public. The external students comprise a significant component of the enrollment of the course. School leavers and university graduates need to acquire personal computing skills for their work, and the course provides them with an opportunity to resume their education, get started in a study of computing or bring their existing technology knowledge up to date. The university permits the Mathematics Department to use the fees generated to acquire and maintain the department's computers and software, enabling the department to establish first-rate facilities.

The department has also begun to design technology-oriented courses specifically for the general public. The spreadsheet is an excellent tool for the 
study of statistics (Arganbright, 1992; Middleton, 1997). Introduction to Statistics using Excel enables students to implement concepts from first principles much as they would do by hand but in a medium that affords them a natural way to experiment and investigate the resulting model. This approach can be supplemented by using a spreadsheet's statistical functions. Excel's statistical analysis tools provide students with a professional experience and many classroom teachers have taken the course to collect teaching ideas. The course also has been incorporated as part of a new postgraduate diploma in computing.

The statistics course was designed for team teaching. Initially a computer oriented mathematician was teamed with a national statistician who had never taught using computers. The procedure represents one way that lecturers lacking IT experienced can acquire computing skills while contributing to instruction.

\section{INCORPORATING APPLICATIONS PROGRAMS INTO MATHEMATICS}

The Mathematics Department had been slow to introduce IT into mathematics teaching - in large measure because few lecturers used computers. Now the situation is changing as technology-adept lecturers are hired and as a teamteaching approach is adopted to train existing staff. In 1997 computers will be used to teach the basic statistics course for the first time. The standard lectures will be presented by the statistics instructor while another lecturer demonstrates how technology can be used. Excel has been chosen because students will be familiar with the program. It provides a nonthreatening introduction to technology for the traditional staff members and is an exceptional tool for teaching statistics.

Practical Computing is an interesting course offered to fourth year students. Team taught by the Mathematics Department and the Director of Computing, the course provides students with practical hands-on skills in software and hardware maintenance coupled with a study of advanced features of Microsoft Office. The students' oral communication skills are strengthened as they research academic topics and make presentations using PowerPoint. As students learn Word's features they strengthen their writing skills as they prepare formal papers and, using Excel, they expand their problem-solving skills by creating mathematical models. Access is used to teach database skills and concepts.

At UPNG spreadsheets are used primarily in a special topics course and in a Numerical Methods course. The latter course employs Excel to study such topics as the zeroes of functions, numerical quadature and differentiation, interpolation, numerical linear algebra and numerical solutions of differential equations. At other universities spreadsheets are used in operations research, linear algebra, calculus, pre-calculus, combinatorics, statistics and probability. 


\section{Illustrative Spreadsheet Examples}

Because the extensive use of spreadsheets is a distinguishing component of the curriculum at the University of Papua New Guinea, this section presents examples used for staff and student classes. Additional graphic examples may be found in the literature (Arganbright, 1993). In using spreadsheets, the primary focus is on developing problem-solving and analysis skills. Wherever possible the examples used involve Papua New Guinea settings.

The model of Figure 1 computes the growth of one-time deposit $p$ (Cell B1) in a savings account at a fixed annual compound interest rate, $r$ (Cell B2). Column A counts years. In Cell C4 the initial deposit is reproduced as the balance $p 0$ at the end of year 0 . The first year's interest $i 1$ is determined in Cell B5 as rp0. The year's new balance is calculated in Cell C5 as $i 1+p 0$. Similar results are computed for subsequent years by copying these formulas. The example becomes particularly interesting to students when they observe that it also provides an introductory population growth model. Often students are astounded by the implications of continued geometric growth at the nation's current rate of 2.5\%-2.8\%. Following this example, students can explore other growth models that assume there is a limiting capacity for growth.

\begin{tabular}{|r|r|r|c|}
\hline & \multicolumn{1}{|c|}{ A } & \multicolumn{1}{c|}{ B } & C \\
\hline 1 & Initial $=$ & 200.00 & \\
\hline 2 & Rate $=$ & $12.0 \%$ & \\
\hline 3 & Year & Interest & Balance \\
\hline 4 & 0 & & 200.00 \\
\hline 5 & 1 & 24.00 & 224.00 \\
\hline 6 & 2 & 26.88 & 250.88 \\
\hline
\end{tabular}

\begin{tabular}{|l|l|l|l|}
\hline & \multicolumn{1}{c|}{ A } & \multicolumn{1}{c|}{ B } & \multicolumn{1}{c|}{ C } \\
\hline 1 & Initial $=$ & 200 & \\
\hline 2 & Rate $=$ & 0.12 & \\
\hline 3 & Year & Interest & Balance \\
\hline 4 & 0 & & $=B 1$ \\
\hline 5 & $=1+\mathrm{A} 4$ & $=\mathrm{B} \$ 2^{*} \mathrm{C} 4$ & $=\mathrm{B} 5+\mathrm{C} 4$ \\
\hline 6 & $=1+\mathrm{A} 5$ & $=\mathrm{B} \$ 2^{*} \mathrm{C} 5$ & $=\mathrm{B} 6+\mathrm{C} 5$ \\
\hline
\end{tabular}

Figure 1 Geometric growth.

Virtually all of the techniques and concepts of elementary statistics can be implemented naturally on a spreadsheet. Figure 2 provides an example of a user-designed layout for a hypothesis test of the population mean. Sample statistics are computed in Cells B2:B4 and the hypothesized population mean and test level are entered in Cells D2 and F2. The computations for the 
conclusion are done by using built-in statistical functions. The chart of Figure 3 is created as part of the previous model and allows users to visualize the hypothesis-testing process.

\begin{tabular}{|r|r|r|r|r|r|r|}
\hline & \multicolumn{1}{|c|}{ A } & B & C & D & E & \multicolumn{1}{c|}{ F } \\
\hline 1 & Parameters and Variables: & & & & \\
\hline 2 & smpl mean $(x)=$ & 51.5 & $H o: \mu=$ & 50 & $\alpha=$ & 0.05 \\
\hline 3 & smpl sd $(x)=$ & 6.45 & $H 1: \mu<>$ & 50 & Crit: $z<$ & -1.96 \\
\hline 4 & $n=$ & 100 & & & Crit: $z>$ & 1.96 \\
\hline 5 & Conclusions: & & & & & \\
\hline 6 & $z=$ & 2.326 & Concl: & Reject & p-value $=$ & 0.02 \\
\hline
\end{tabular}

Figure 2 Hypothesis test for population mean.

\section{NEW ADVANCES AND FUTURE CHALLENGES}

In 1996 the university's new Vice Chancellor established IT as a high academic priority and a new campus-wide fiber optic network was completed. In 1997 the initial phase of central laboratory construction has been completed and staffing levels in computing have been increased - events that should enable the Mathematics Department's efforts to reach a wider segment of the university.

The UPNG Mathematics Department's efforts to revitalize IT use has made a positive impact at the university. In a country where educational institutions cannot supply students with an extensive range of specialized software, Microsoft Office works well as a fundamental tool. While the university will continue to face difficulties supplying all of the essential IT knowledge and skills, a solid foundation provides students, staff and the public with fundamental IT skills. For each of the courses the department has prepared extensive notes, and the notes are being compiled into books that will be available for short courses and self-teaching at the university as well as throughout the country.

Nonetheless, more remains to be done. A national staff must be equipped to replace the overseas staff who are currently teaching IT courses. Many departments need additional training in IT. The university is looking for external funding to maintain and extend IT activities, and the daunting need to maintain staffs' IT competence must continue as technology changes rapidly.

Arganbright, D. (1992) Using Spreadsheets in Teaching Statistics, Statistics for the Twenty-first Century (eds. F. Gordon and S. Gordon), Mathematical Association of America, Washington D.C., 226-242. Arganbright, D. (1993) Practical Handbook of Spreadsheet Curves and Geometric Constructions. CRC Press, Boca Raton, FL. 
Cartwright, T. (1993) Modeling the World in a Spreadsheet. Johns Hopkins, Baltimore, MD.

Middleton, M. (1997) Data Analysis Using Microsoft Excel. Duxbury Press, Belmont, CA, 1997.

\section{BIOGRAPHY}

Deane Arganbright is Professor and Head of the Mathematics Department of the University of Papua New Guinea. He teaches mathematics and computer science, and is Chair of the University Computer Committee. Professor Arganbright received his $\mathrm{Ph} . \mathrm{D}$. in mathematics (finite groups) at the University of Washington (USA), and is an authority on the use of spreadsheets for mathematical education, modeling and visualization. He has presented invited addresses at national and international conferences, and is the author of Mathematical Applications of Electronic Spreadsheets (McGraw-Hill, 1984) and Practical Handbook of Spreadsheet Curves and Geometric Constructions (CRC Press, 1993). He is currently developing mathematics and statistics material designed for use in Papua New Guinea. 